\title{
Developing health and social care planning in collaboration
}

\author{
Margareta Rämgård ${ }^{1}$, Kerstin Blomqvist ${ }^{2}$ and Pia Petersson ${ }^{2}$ \\ ${ }^{1}$ Department of Care Science, Faculty of Health and Social Society, Malmö University, Malmö, Sweden and ${ }^{2}$ School of Health and Society, \\ Kristianstad University, Kristianstad, Sweden
}

\begin{abstract}
Collaboration between different professions in community care for older people is often both difficult and complex. In this project, a participatory action research (PAR) was conducted in order to support the professions involved in the care for older people to develop individualized health and social care plans. Cases from daily work were discussed in different professional groups over a period of one year. A key finding was that lack of knowledge regarding the other professions' field of expertise and their underlying professional culture and values was a barrier in their collaboration. However, as the continuous reflective dialogue process progressed, the participants began to reflect more about the importance of collaboration as a prerequisite to achieve the best possible care for the recipient. This process of reflection led to the often complex needs of the care recipients being given a more central position and thus care plans being better tailored to each person's needs.
\end{abstract}

\author{
Keywords

\section{History} \\ Received 18 March 2014 \\ Revised 8 August 2014 \\ Accepted 29 December 2014 \\ Published online 30 January 2015
}

Action research, communication, health and social care, interprofessional collaboration

\section{Introduction}

In Sweden, care is categorized into healthcare and social care and these are handled by different administrative authorities and they are regulated by two different sets of laws: the Health and Medical Services Act (SFS, 1982) and the Social Services Act (SFS, 2001). This division can be the cause of some problems due to the gaps that occur between the organizations. Additionally, the often complex individual care needs are met by a range of different professionals, each with their own professional culture. Research conducted in some of the Nordic countries indicate that this specialization widens the gap between hospital specialists and community care (Duner, 2013; Johannessen \& Steihaug, 2014). In an attempt to overcome these problems, each care provider's function and responsibilities have been clarified through regulations (SOSFS, 2005).

The studies (Edgren, Lagercrantz, \& Øvretveit, 2005; Nosbusch, Weiss, \& Bobay, 2010; Petersson, Springett, \& Blomqvist, 2009) on care planning indicate that communication difficulties are impeding factors to successful collaboration. Difficulties in communication is not only a problem between professions but also between professionals within one profession employed by different organizations. A lack of joint platforms for sharing information and a lack of knowledge about the other organizations' goals are other obstacles for collaboration (Nosbusch et al., 2010). Solutions suggested to address these issues include improving communication skills and formalizing the care planning process by introducing standard procedures and routines for various professions (Nosbusch et al., 2010; Petersson et al., 2009). In order to better understand the collaboration

Correspondence: Dr Pia Petersson, School of Health and Society, Kristianstad University, Kristianstad, 291 88, Sweden. E-mail: pia.petersson@hkr.se between functionally differentiated organizations, models that describe collaboration as structures as well as development processes have been developed. Models considering collaboration in a purely linear manner have been criticized, as collaboration involves complexity and dynamic processes (Furenbäck, 2012). In a meta-analysis, Mandell and Steelman (2003) identified a few key aspects to achieve successful collaboration, one is that the professionals must actually desire to collaborate; and another is to address and discuss the different understandings of the problems and what solutions should be used to address them.

Collaboration in individualized care planning involves both work management and social processes (Furenbäck, 2012). For instance, care planning that takes place in the individual's home involves inter-professional collaboration. At the same time, social processes are initiated between care givers and the care recipients, as well as between different professional groups. However, care plannings at home are still rare and collaboration need to be developed (Socialdepartementet, 2012). Difficulties in interprofessional communication may be caused by the strong sense of identity that characterizes professional belonging (Abbott, 1998). Abbott (1998) uses the concept of jurisdiction to refer to the rights to perform certain tasks, and the responsibilities, of different professions. Each profession has its own system of training and is governed by specific legislation and, as a consequence, they each control a particular knowledge domain. In situations with several professions involved, such as the community health and social care services for older people, conflicts may emerge concerning who has the interpretative prerogative.

According to Abbott (1998), professional groups working in community health and social care can be considered as professions since they are scientifically educated, their training is designed to ensure a specific form of expertise, and they are expected to take independent decisions based on their own assessments (Rämgård, 2010). 
According to Swedish law, registered nurses (RN), social workers and primary care physicians (GP) must collaborate in care planning. Additionally, physio- and occupational therapists and enrolled nurses often participate in care planning at home. The municipality is the responsible authority for RNs and the social workers, but they are regulated by different sets of laws: the HSL (SFS, 1982) and SOL (SFS, 2001). The primary care is the responsible authority for the GPs who are regulated by the HSL. This division of responsibility and distinct sets of laws that govern the professional groups involved in individualized care planning can be an obstacle both to work management and social processes. Nevertheless, Abbott (1998) believes that if a practical problem needs to be solved, there is a chance that professions might liberate themselves from their preconceptions. If focus is placed on the problem at hand, new actions arise. This outcome is not automatic; it requires trust between the professional groups working in different functions (Petersson, 2009; Rämgård, 2010).

\section{Methods}

This study employed participatory action research (PAR), a methodology which builds on involving the individuals who are concerned by a particular problem or issue (Stringer \& Genat, 2004). Such involvement can lead to practical or ideological change. The role of the researcher is in PAR, according to Stringer (1999) " ... not that of an expert who does research but that of a resource person. He or she becomes a facilitator or consultant who acts as a catalyst to assist stakeholders in defining their problems clearly and to support them as they work toward effective solutions to the issues that concern them...' (p. 25). Participatory action research is often described as a process involving three phases, a look, think and act phase in an interacting spiral. In short, the look phase is about defining the problem, during the think phase the issues are interpreted and analyzed. Finally, the act phase is about resolving the problems (Stringer, 1999). Central concepts within PAR are dialogue, participation and reflection over norms and values (Lundberg \& Starrin, 2001). This paper presents a PAR project about developing health and social care planning in collaboration (HSCPC) for older persons living at home. Health and social care planning in collaboration is regulated by Swedish laws as an obligation to perform when health and social care is given by the staff from both social and health services. Notwithstanding that the legislation has existed since 2010, the introduction of HSCPC has proved difficult to achieve. The aim was to identify barriers and opportunities for inter professional collaboration and to attempt to use PAR in supporting HSCPC.

\section{Study context}

A PAR project about HSCPC for older persons at home based on interprofessional collaboration was initiated by RNs in three different municipalities in southern Sweden. The RNs had the overall medical responsibility for municipal health care (Ödegård \& Andersson, 2006), our role as action researchers was to participate and to facilitate the process (Stringer, 1999).

\section{Data collection and analysis}

A total of 18 persons, all women, from the three municipalities participated in the project. Each municipality was represented by enrolled nurses, RNs, physio- or occupational therapists, social workers, senior managers and GPs. All except one GP had long experience of home care. They were chosen by their managers based on their commitment to issues regarding individualized care planning.
The participants met on six occasions, every second month, over a period of one year. They were asked to bring one case from each municipality about an individualized care planning process which they found difficult and complex. At each meeting, one case was shared and discussed in the whole group. The group was then divided into smaller dialogue groups according to their profession. A reflecting dialogue took place and the following questions were used as a point of departure: What facts do we have? What additional facts do we need? What needs to be done? How should it be done? Who should do it? Finally, the whole group met again to discuss and reflect upon the conclusions that each professional group had reached. Between these meetings they tried out HSCPC in their own municipalities. Insights from this was reflected during the following meeting.

All discussions were recorded, transcribed verbatim and analyzed using conventional content analysis (Hsieh \& Shannon, 2005). All researchers were present at all meetings, the transcribed data were read by the researchers separately and the analysis was performed both individually and together. Meaning units were extracted and categorized and our tentative analyses were continually discussed with the participants in reflective dialogues.

The study was approved by the R\&D Ethical committee at Scania Association of local authorities. The cases from each municipality were made anonymous, quotes were coded according to profession, not to individual participants.

\section{Results}

The action research cycle involves three phases: (1) a look phase, (2) a think phase and (3) an act phase (Stringer, 1999). The findings from these three phases are presented below.

\section{Look phase: insights about barriers for interprofessional collaboration}

In this phase, a number of barriers to collaboration were identified. One was organizational structures and geographical distances. Other barriers concerned uncertainty regarding the fields of expertise, knowledge and value systems of other professional groups.

\section{Organizational structure and geographical distance}

The participants expressed that they often lacked enough medical information about the care recipient when he or she had been hospitalized, this made them feel unsure in the home care situation. Additionally, they felt unsure about who carried the formal responsibility when they discovered health problems and complications during home visits.

All professional groups did not participate in the individualized care planning at the hospital, which prevented access to information. This also had medical consequences, since it resulted in confusion concerning medication. The RNs explained that problems in managing medication were often first discovered when the enrolled nurses who provided daily care in the home observed that the medication was not working properly. Difficulty in obtaining information from the hospital to the care plan was highlighted in a dialogue between two RNs:

RN1: You have done care planning for her, haven't you?

RN2: No, never.

RN1: How did you get in touch with her then?

RN2: Through the enrolled nurse, that is often the way it happens.

RN1: The medication isn't working properly and she has been taking the wrong medicine, and so on, that is how I was called in. 
The participants were often unsure about what information had been given to the care recipients at the hospital concerning their medical condition, and above all what their prognosis was. This was experienced as particularly troublesome in the cases where the prognosis was that the care recipient approached a palliative phase. According to the participants, the important conversations with the care recipients and their family were obstructed by this lack of information.

The participants also felt that the deficiencies in transmitting information were a problem when several actors were involved in the care of individuals suffering from multiple conditions. The quote below (by one enrolled nurse) illustrates the enrolled nurses need for joint meetings with professionals from both hospital- and community-care, where information could be exchanged and where all professional group involved would participate.

What if we had just been able to sit down together and they had explained to us what kind of report they want us to make. For instance, how the woman has reacted to pain killers. Does she get better or does she get worse? For instance, I feel that it makes her groggy.

As the participants felt unsure who should do what in the care process, they used initially legislation to sort out who was formally responsible. The social workers looked for support in legislation, which they divided into a social field of responsibility, as opposed to the responsibility for health and medical care. The RN were less inclined to talk about this division, while the senior managers tended to base their discussions on both sets of legislation, the Health and Medical Services Act and the Social Services Act.

\section{Uncertainty regarding knowledge and different value systems}

The participants discussed each other's areas of knowledge and how the different professions contributed to documentation in the care (planning) documents. They noted that different professions used a terminology specific to each profession and used different expressions to describe health conditions and diagnoses. The quote below, by one GP, illustrates how the GPs' discussed the challenge of expressing a prognosis to make it understood also by enrolled nurses:

Or that you write 'in a late palliative stage' when no additional treatment is required. How do you express that to an enrolled nurse? 'Dying patient'?

The lack of knowledge of other professions' knowledge base and of each other's tasks was another source of frustration. This was particularly noticeable in contacts between professional groups representing medical care and those representing social care. One such difficulty is highlighted in a dialogue between two social workers:

I think it is interesting to listen, when you listen to nurses, doctors, how they speak about us. It's this thing about having too many different ways of seeing issues. And they do not have the knowledge [...] about how we make investigations in casework.

Based on conceptions of other's professional values, the participants discussed their respective professional roles, in order to reach a common agreement. Staff with a background in medical care prioritized medical aspects, while staff from social care felt that medical concerns were often given an interpretative privilege. On the other hand, physio- and occupational therapists felt that medically trained staff often forgot maintaining the patient's functional abilities as expressed by one physiotherapist:

I feel that it is so typical, I mean when a nurse is telling you about it, you get everything in detail, what happened medically $[\ldots]$ but you there is not lot about function, what it's been like. He can't walk, they have no activity analysis.

\section{Think phase: insights of opportunities for collaboration}

During the think phase, the participants began to see more opportunities in their inter-professional collaboration. The reflections in the dialogue groups brought unexpected insights about collaboration with the care recipient.

\section{Respecting the others knowledge and perspectives}

After several meetings, the participants began to find shared standpoints. The conversations were more and more characterized by a sense of community and trust, as well as greater understanding for the others' points of view. Less and less did the participants point at shortcomings in the other professions as barriers to their efforts to improve the collaboration. The reflections in the dialogues allowed them to see how their own knowledge and others' complemented each other. Additionally, their understanding of the perspectives of the other professionals grew as the study progressed.

RNs and GPs often devoted a great deal of energy to informing and motivating the care recipient into agreeing to their suggestions, while the social workers highlighted the care recipients' right to make autonomous decisions. However, gradually the social workers expressed conflicting feelings:

The enormous 'health care thinking' that you mostly get from nurses, while we are a bit more laid back, we are colder. There is a danger to that. Like my nurse said in our team, he would have been dead if he hadn't been [persuaded]...

In the course of the conversations, participants also started to reflect on how easy it was to only reason based on their own norms and values, and that they often took for granted that everyone shared their values. This made them consider that they might have to change their own standpoints.

The participants also mentioned something they called "professional anguish', They felt a sense of inadequacy as individuals to achieve the aims of their own profession. As the work was demanding, and many tasks had changed over time, they occasionally experienced insecurity in their own professional identities, this sometimes led them blaming other professional groups. One of the senior managers express this frustration in the following quote, "we need to work with our own anxiety, instead of transferring it onto others',

As the interprofessional dialogue deepened, the previous hierarchical structure progressively disappeared and the profession began to understand different perspectives. One of the GPs reflected:

It is very easy to assume that everyone understands things the same way to begin with. We use our own values and perspectives of the world as a point of departure, and assume that everyone sees things in a similar way.

Once the participants had engaged in a deeper dialogue about each other's underlying values, they increasingly began to question their previous categorization into clearly defined areas 
of responsibility, and regarded it as being too narrow. Further on, they began to reflect more about questions of collaboration and attaining shared understandings, rather than about the issue of who was responsible for what.

\section{Giving care recipients a more central place}

As the participants' understanding of each other grew and sense of community began to develop, they devoted more attention to the needs of the individual care recipient.

In the earlier group conversations, the social workers tended to emphasize the care recipient's right to make autonomous decisions as the most absolute central aspect, while health care staff were more defensive yet rather ambivalent in their thinking. One GP reflect on this in the quote below:

We miss a lot of things where we might have been able to make life easier for them (the older people). We bring our knowledge and our education and our values, and then he has a completely different background and different wishes and thoughts when you tell him something.

All professions increasingly began to ask for information about the care recipients' background and previous social life. They felt that this knowledge was crucial for providing good care. From initially, mainly, having used their own professional values as a point of departure, the reflective dialogue made the participants' attempt to see reality from the care recipient's perspective. Finding out more about their previous life history became a key aspect, as this allowed them to familiarize themselves with that person's point of view. One occupational therapist reflected on this matter below:

Actually, we don't know how long he has been or how he functioned earlier... we need to find out what he wants himself, but the difficulty is that he do'sn't understand the medical picture.

New ways of understanding behaviors which previously had been considered irrational emerged. For instance, they suddenly came to the conclusion that the reason why a care recipient didn't follow medical prescriptions was not necessarily an initial sign of dementia. Instead, it might have been a result of the staff failing to inform the care recipient about his or her medical condition in a comprehensible manner. In this quotation an enrolled nurse expresses this:

He may have received information, of course, but not understood. If you don't even know what the body looks like inside, when the doctor explains you don't understand anything.

\section{Act phase: transforming insights into practice}

One of the three participating municipalities decided to continue the project and implemented HSCPC as part of their regular work. They based their continued work on a structure that enabled all professions to meet in the home of the care recipient and make joint individual care plans. An evaluation has been performed and is presented elsewhere (Sundström et al., 2013). In another municipality, one GP started in a small scale by devoting one afternoon a week to community care for older people, and for home visits if when needed. This municipality has recently decided to implement HSCPC.

\section{Discussion}

A prerequisite to achieve individualized care planning for older people in collaboration is to overcome the barriers of different organizational structures and the geographical distances. Another prerequisite which takes some time to achieve is for the staff to become aware of each other's values as professions. This PAR project using reflective dialogues and the opportunity to test individual care plannings between meetings resulted in knowledge transfer and made the professional groups more aware of, both their own and others', thoughts and values; a fundamental result in PAR (Lundberg \& Starrin, 2001). Decisions that previously were based on the participants' own professional background became more complex. Abbott (1998) contends that most professional groups have a professional identity that strengthens their internal cohesion. This has been clarified and confirmed by researchers in a range of fields, including public health and nursing (Axelsson \& Axelsson, 2009). High-status professionals may be an obstacle to the interprofessional collaboration adversely, since each group is accorded different interpretive privileges, depending on their status and responsibilities (Abbott, 1998). This type of hierarchical interaction is referred to as 'tribalism', by Baxter and Brumfitt (2008). Participants remarked the fact that several different professions are involved in planning for each individual can both be an opportunity and an obstacle in individualized care planning. Skau (2007) argues that the knowledge of different professions in community care complement each other, but they also often overlap and compete. The perception of the own and others' professional identities most likely contribute to whether professional groups see each other as rivals or as complementary resources. In this study, these perceptions were influenced by the extent to which the different professions communicated with each other over time.

The results of the study can be understood in relation to Abbott's (1998) argument that rivalry between professions may decrease in context of close inter-collaboration at the workplace. Home care is generally provided by different professions coming separately, thus they are rarely present at the same time. There is thus a need to communicate between professions about joint care planning in the home. These conclusions are in line with earlier research by Edgren et al. (2005), Petersson (2009) and Nosbusch et al. (2010), who argue that collaboration may be improved through organized interprofessional communication about knowledge, values and perspectives. PAR has proved to be a viable approach to systematically support and enable this communication. When the participants were given the opportunity to reflect about their own professional core values, in relation to the cases, consensus was not necessarily reached concerning what solution should be used. Nevertheless, the dialogue did contribute, over time to an "altruistic" approach, where the participants respected each other's knowledge in a less protectionist manner than before. They began to perceive their own shortcomings as well as their strengths. In their studies about interprofessional collaboration and leadership, Axelson and Axelson (2009) pointed to the importance of altruism to achieve positive collaboration. Similar results can be noted in the present study. By breaking up territorial barriers between professions, an understanding of each other's professional norms and values is improved, and new knowledge can thereby be developed through a form of altruism in the group.

One important result from the study is that when the participants gained increased understanding for each other's work and values, they also came to the conclusion that they frequently used their own professional values as a point of departure in their approach to caring. As a result of this insight, participants moved the focus in their discussion from the issue of 
who is responsible for what, to focus more on providing the best possible care for each individual care recipient. They also began to reflect more over the individual person's needs, based on this individual's life world and abandon the idea that some other actor may possess a better or more valid form of knowledge, which is a fundamental step in the direction of what is known as “person-centered care"' (Kitwood, 1997; Rogers, 2004).

A successful PAR-project requires prolonged engagement in the field as time is needed for building trust between participants (Grant, Nelson, \& Mitchell, 2008; Petersson, 2009; Stringer \& Genat, 2004). Since the participants represented different professions with different value systems and with hierarchical barriers due to different fields of expertise, there was a risk that conflicts might obstruct collaboration. The project was therefore designed to give various professions the opportunity to get to know each other's professional standpoints by keeping the dialogues in a standardized form over a period of time. A sufficient number of meetings to provide the conditions for building trust between the professions were held. This resulted in a flattening of the hierarchical relationships within the group and promoted a sense of equality. The participants began to respect each other's point of view, and instead of defensively guarding their own areas of interest, invite others to share the conclusions and knowledge they had reached during the process.

Another factor highlighted in the literature about PAR is member checking. Therefore, each meeting started by giving feedback of what had been discussed during the previous meeting. This made it possible for the participants to review the raw data and their view of our interpretations ensured the credibility of these interpretations. By letting the participants tell their stories and reflect on the differences between their views, they began to see health and social care planning in a new way. Thus, the participants own stories became a concrete and helpful tool in the developmental process.

Finally, the practical applicability of a project's findings strengthens the credibility of PAR, since one of the core objectives is to create knowledge that the participants can use (Stringer \& Genat, 2004). The intention of this project to develop HSCPC in all the participating municipalities was not fully reached. One of the participating municipalities introduced HSCPC as part of their regular activities and a second municipality has started in small scale and is now about to introduce the model.

\section{Concluding comments}

Well-coordinated health care requires that care providers listen to and collaborate with each other, with the care recipients and their relatives. Interprofessional collaboration also presupposes that the professionals involved have a common objective and vision. Thus, it is not sufficient that each profession and organization separately conduct a conversation with the care recipient, since they use different points of departure in their work. Effective communication is crucial, and can be achieved through reflective inter-professional dialogues, to achieve person-centered care (Pel-Zang, 2010). Such conversations need to be ongoing, regular and incorporated in the organizational structure.

\section{Declaration of interest}

The authors report no conflict of interest. The authors alone are responsible for the content and writing the paper.

\section{References}

Abbott, A. (1998). The system of professions: An essay on the division of export labor. Chicago: University of Chicago Press.

Axelsson, B., \& Axelsson, R. (2009). From territoriality to altruism in interprofessional collaboration and leadership. Journal of Interprofessional Care, 23, 320-330.

Baxter, S.K., \& Brumfitt, S.M. (2008). Professional differences in interprofessional working. Journal of Interprofessional Care, 22, 239-251.

Duner, A. (2013). Care planning and decision-making in teams in Swedish elderly care: A study of interprofessional collaboration and professional boundaries. Journal of Interprofessional Care, 27, 246-253.

Edgren, L., Lagercrantz, K., \& Øvretveit, J. (2005). Inter-agency cooperation and discharge planning for older people in South Sweden. Vård i Norden, 25, 53-58.

Furenbäck, I. (2012). Utveckling av samverkan - ett deltagarorienterat aktionsforskningsprojekt inom hälso-och sjukvård ( $\mathrm{PhD}$, Nordic School of Public Health, Gothenburg) [Swedish].

Grant, J., Nelson, G., \& Mitchell, T. (2008). Negotiating the challenges of participatory action research: relationships, power, participation, change and credibility. In P. Reason \& H. Bradbury (Eds.), The Sage handbook of action research (pp. 589-601). London: Sage Publications.

Hsieh, H.-F., \& Shannon, S.E. (2005). Three approaches to qualitative content analysis. Qualitative Health research, 15, 1277-1288.

Johannessen, A.-K., \& Steihaug, S. (2014). The significance of professional roles in collaboration on patients' transitions from hospital to home via an intermediate unit. Scandinavian Journal of Caring Sciences, 28, 364-372.

Kitwood, T. (1997). Dementia reconsidered: The person come first. Buckingham: Open University Press.

Lundberg, B., \& Starrin, B. (2001). Participatory research-Tradition, theory and practice. Karlstad: Karlstad University Studies.

Mandell, M.P., \& Steelman, T.A. (2003). Understanding what can be accomplished through interorganisational innovations. Public Management Review, 5, 197-224.

Nosbusch, J., Weiss, M., \& Bobay, K. (2010). An integrated review of the literature on challenges confronting the acute care staff nurse in discharge planning. Journal of Clinical Nursing, 20, 754-774.

Ödegård, S., \& Andersson, D. (2006). Insulin treatment as a tracer for identifying latent patient safety risks in home-based diabetes care. Journal of Nursing Management, 14, 116-127.

Pel-Zang, R. (2010). Time to learn: Understanding patient-centered care. British Journal of Nursing, 19, 912-917.

Petersson, P. (2009). Att göra abstrakta begrepp och komplexa situationer konkreta - en avhandling om deltagarbaserad aktionsforskning i svensk vård och omsorg (Dissertation, Örebro) [Swedish].

Petersson, P., Springett, J., \& Blomqvist, K. (2009). Telling stories from everyday practice, an opportunity to see a bigger picture: A participatory action research project about developing discharge planning. Health and Social Care in the Community, 17, 548-556.

Rämgård, M. (2010). Närsjukvård - Samverkan mellan olika professioner $i$ hemsjukvården Skriftserie 2010:5. Malmö: FoU Skåne [Swedish].

Rogers, C.R. (2004). On becoming a person: A therapist's view on psychotherapy. Boston: Houghton Mifflin.

SFS (1982). Hälso-och sjukvårdslagen (The Health and Medical Service Act) [in Swedish]. Svensk författningssamling 1982:763.

SFS (2001). Socialtjänstlagen (The Social Services Act) [Swedish]. Svensk författningssamling 2001:453.

Skau, G.M. (2007). Mellan makt och hjälp: om det flertydiga förhållandet mellan klient och hjälpare (3rd ed.). Stockholm: Liber [Swedish].

Social departementet. (2012). Sammanhållen vård och omsorg om de mest sjuka äldre 2012. Stockholm: Socialdepartementet [Swedish].

SOSFS (2005). Socialstyrelsens föreskrifter 2005:27. Samverkan vid in och utskrivning av patienter i sluten vård (Co-operation in connection with registration and discharge of patients in hospital care) [Swedish].

Stringer, E. (1999). Action research (2nd ed.). London: Sage Publication.

Stringer, E., \& Genat, W. (2004). Action research in health. New Jersey: $\mathrm{J}$ Pearson Education.

Sundström, M., Blomqvists, K., Petersson, P., Rämgård, M., \& Valand, L. (2013). Inte samma mall för alla - om vård och omsorgsplanering $i$ samverkan. Kristianstad: Kristianstad University Press [Swedish]. 